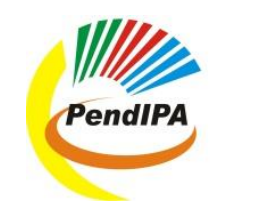

\title{
Analisis Tingkat Disposisi Kreatif dan Posisi Disposisi Kreatif Siswa SMP dalam Pendidikan IPA

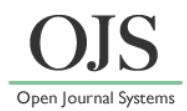

\author{
Anggit Permanasari*, Ari Widodo, Ida Kaniawati \\ Sekolah Pascasarjana, Jurusan Pendidikan IPA, Universitas Pendidikan Indonesia \\ *Email: permanasari96@upi.edu
}

DOI: https://doi.org/10.33369/pendipa.6.1.308-314

\begin{abstract}
This study aims to determine the level of creative disposition and creative disposition position of junior high school students in science education. The research method used is descriptive with the type of survey. The sample in this study amounted to 73 junior high school students from several schools in Muara Enim, South Sumatra. The instrument used in this study was a closed questionnaire for responses to each student's self-report regarding several statements of creative disposition and creative disposition position. The results showed that the students' creative disposition and creative disposition position were at an average score of $75 \%$ in the medium category. Meanwhile, the highest average score of the creative disposition indicator is found in the collaborative indicator $78 \%$ and the curiosity indicator $78 \%$ from the aspect of the student's creative disposition position compared to peers. Both male and female students have the same and balanced average, but male students are more dominant in the aspects of persistence and collaboration while for female students have a more dominant score on the collaboration aspect only. Creative dispositions can affect students' creative dispositions, and vice versa. Creative disposition and creative disposition position are two aspects that must also be supported and developed in the context of students' creativity in science education.
\end{abstract}

Keywords: Creative disposition; creative disposition position; Junior high school; Survey Research.

\begin{abstract}
ABSTRAK
Penelitian ini akan bertujuan untuk mengetahui tingkat disposisi kreatif dan posisi disposisi kreatif siswa SMP dalam pendidikan IPA. Metode penelitian yang dilakukan merupakan metode deskriptif dengan jenis penelitian survei. Sampel yang terdapat dalam penelitian ini berjumlah 73 orang siswa SMP dari beberapa sekolah di muara enim, Sumatera Selatan. Instrumen penelitian yang digunakan yaitu berupa kuesioner tertutup untuk tanggapan atas laporan diri setiap siswa terkait beberapa pernyataan disposisi kreatif dan posisi disposisi kreatif. Hasil penelitian menunjukkan bahwa disposisi kreatif dan posisi disposisi kreatif siswa berada pada presentase rata-rata skor $75 \%$ dengan kategori sedang. Sedangkan rata-rata skor tertinggi dari indikator disposisi kreatif terdapat pada indikator kolaboratif $78 \%$ dan pada indikator keingintahuan $78 \%$ dari aspek posisi disposisi kreatif siswa dibandingkan dengan teman sebaya. Hasil perbandingan baik dari siswa laki-laki maupun perempuan memiliki rata-rata yang sama dan seimbang, akan tetapi pada siswa laki-laki lebih dominan pada aspek kegigihan dan kolaboratif sedangkan untuk siswa perempuan memiliki skor yang lebih dominan pada aspek kolaborasi saja. Disposisi kreatif dapat mempengaruhi posisi disposisi kreatif siswa, begitupun sebaliknya. Disposisi kreatif dan posisi disposisi kreatif merupakan dua aspek yang juga harus didukung dan dikembangkan dalam konteks kreativitas siswa dalam pendidikan IPA.
\end{abstract}

Kata kunci: Disposisi Kreatif; Posisi Disposisi Kreatif; Siswa SMP; Penelitian Survei. 


\section{PENDAHULUAN}

Kreativitas memiliki peranan yang sangat penting dalam proses pembelajaran untuk siswa dan guru. Terutama untuk siswa, kreativitas harus ada dalam diri siswa sebagai potensi disposisi kreatif. Banyak pendapat dan gagasan yang menyatakan bahwa setiap orang memiliki potensi kreatif dan naluri untuk menciptakan kreativitas (Márquez dkk., 2016; Runco, 2003). Mengembangkan potensi siswa agar menjadi seseorang yang kreatif merupakan salah satu tujuan sekaligus fungsi dari pendidikan di Indonesia (UU No. 20 thn 2003).

Hal ini juga dapat dilihat dari adanya perubahan kurikulum nasional KTSP menjadi kurikulum 2013 yang ditunjukkan untuk membentuk individu yang kreatif (Wahyudi dkk., 2018). Seseorang yang kreatif juga harus dilihat tidak saja dari sudut pandang keterampilan dan kemampuannya saja, akan tetapi karakter kreatif siswa juga perlu dikembangkan. Untuk mengembangkan kreativitas siswa, diperlukan faktor-faktor seperti disposisi kreatif siswa yang bersifat kepribadian dan motivasi yang tentu sangat penting (Csikszentmihalyi, 1998).

Membekali dan mengembangkan kreativitas siswa tidaklah mudah, terdapat beberapa faktor yang dapat mempengaruhi seseorang menjadi individu yang kreatif. Hal ini sesuai dengan studi literatur sebelumnya yang telah mengkategorikan faktor-faktor yang mempengaruhi kreativitas siswa dibagi menjadi empat dimensi yaitu (1) seseorang yang kreatif, memiliki karakteristik yang dapat dikaitkan dengan pengalaman pribadi, sifat kognitif, kepriadian khusus dan emosional (2) proses kreatif, ditekankan pada cara-cara kreatif dalam mensintesis, memperbaiki ide-ide dan menambahkan ide-ide baru yang belum ada kedalam pengetahuan yang sudah ada (3) produk kreatif, meliputi penemuan produk-produk kreatif yang inovatif, bernilai, original dan bermanfaat untuk masyarakat umum (4) press atau penekanan, dimana difokuskan pada peran penting lingkungan yang dapat mempengaruhi individu yang memiliki kreativitas atau pun organisasi tertentu (Kang, 2020b; Rhodes, 1961).

Salah satu faktor yang dijelaskan sebelumnya, menekankan bahwa lingkungan menjadi faktor yang berperan dalam mempengaruhi kreativitas siswa. hal ini berkorelasi positif dengan pendidikan IPA yang identik dekat dengan alam dan lingkungan. seperti pada studi yang menyatakan bahwa membuat dan menciptakan pembelajaran yang kreatif dapat mempengaruhi siswa untuk lebih tertarik dan bersemangat dalam pembelajaran IPA di sekolah (Suciani \& Prima, 2020). Hal ini juga sejalan dengan pernyataan Association for Science Education (2010) yang mengungkapkan bahwa tujuan utama pendidikan sains seharusnya memungkinkan siswa untuk menentukan keputusan dan tindakan yang kreatif untuk dapat mempengaruhi masyarakat dan lingkungan yang ada disekitar. Untuk itu, pembelajaran IPA di sekolah dapat menjadi bekal kreativitas siswa untuk diterapkan dalam kehidupan sehari-hari dengan alam dan sekitarnya.

Selain faktor lingkungan, strategi dalam membuat metode pembelajaran termasuk salah satu yang dapat mempengaruhi proses dan produk kreatif dalam pembelajaran. Sebagai guru kreatif harus memilik kesiapan untuk mempengaruhi kreativitas siswa caranya dapat melalui metode belajar-mengajar, pemikiran kreatif guru, dukungan emosional dan juga dengan menjadi panutan kreatif bagi siswa mereka (No dkk., 2007; Kang, 2020). Terdapat beberapa metode pembelajaran yang disarankan salah satunya metode investigasi yang dapat meningkatkan dan mengembangkan kreativitas siswa dalam pembelajaran IPA yang harus disiapkan dengan mendorong siswa dalam mengembangkan keterampilan inkurinya (Lawson, 2001; Mumford dkk., 2010; Sukarso dkk., 2019). Untuk itu, perlu adanya perencanaan yang matang untuk menentukan metode pembelajaran yang kreatif dan inovatif.

Setelah mempersiapkan metode dan strategi dalam pembelajaran, kreativitas juga dapat dinilai dan diukur dengan berbagai macam penilaian. Salah satunya dengan menilai tindakan atau perilaku yang dikerjakan oleh siswa dalam pembelajaran (Sukarso dkk., 2019). Kreativitas juga dapat dinilai dengan dua cara yaitu pertama, dapat dinilai dari ciri-ciri aptitude seperti kelancaran, keluwesan, orisinalitas dan kerincian dan cara yang kedua dengan non aptitude, termasuk didalamnya motivasi, perilaku, tempramen dan komitmen dalam menyelesaikan tugas-tugas (Mukhlis \& Tohir, 2019). Dalam penelitian terdahulu didapatkan bahwa 
mengamati perilaku anak dapat menjadi fokus dari penilaian pemikiran kreatifnya (Robson \& Rowe, 2012). Pada draft kerangka kerja terbaru juga yang telah dirancang oleh OECD (Organization for economic cooperation and development) saat ini sudah mengambangkan penilaian pemikiran kreatif PISA 2021 yang diupayakan untuk dapat mendorong perubahan yang positif dalam kebijakan pendidikan dan pedagogik. Untuk itu, banyak cara untuk dapat menilai kreativitas tergantung dari sisi mana kita akan mengukur dan menilainya.

Sayangnya, dalam penilaian dari hasil survei global creativity index 2015 Indonesia termasuk salah satu negera yang masih rendah dalam predikat tingkat kreativitasnya. Terbukti pada peringkat ke 115 dari 139 negara di tempati oleh Indonesia yang artinya masih tergolong rendah pada kemampuan dan keterampilan berpikir kreatifnya (Florida dkk., 2015). Hal ini dikarenakan kurangnya persiapan dalam memenuhi faktor-faktor yang mempengaruhi kreativitas yang telah dijelaskan sebelumnya, baik dari segi pengetahuan, produk, proses, dan lingkungan. Karena kreativitas tidak hanya berada dalam sistem otak kita, tetapi muncul dari interaksi dengan pemikiran orang dalam konteks sosial budaya (Csikszentmihalyi, 1998; Kang, 2020). Sampai saat ini, sebagian besar penelitian hanya melakukan kajian tentang keterampilan berpikir kreatif dan kreativitas siswa saja, namun hanya sedikit yang membahas dan meneliti tentang disposisi kreatif siswa. Padahal pengibaratan antara disposisi dan keterampilan yang tidak dapat dipisahkan yaitu seperti dua mata uang yang saling melengkapi (Ari Widodo, 2015).

Disposisi merupakan kecenderungan seseorang untuk berpikir dan melakukan sesuatu dibawah kontrol sadar dan secara sukarela yang disengaja berorientasi untuk tujuan yang lebih luas lagi (Noyes, 2000). Disposisi juga ada yang manyebutnya sebagai Habits of Mind (HOM) atau kebiasaan berpikir seseorang (Widodo, 2021). Seseorang yang memiliki kebiasaaan dan disposisi untuk berprilaku kreatif merupakan suatu hal yang sangat penting (Csikszentmihalyi, 1998; Márquez dkk., 2016). Guru dapat dengan rajin merencanakan pengalaman belajar yang membantu anak-anak memperoleh keterampilan dan disposisi untuk menggunakan keterampilan tersebut (Ros-Voseles \& Fowler-Haughey, 2007).

Disposisi kreatif dapat juga didefinisikan dengan pola perilaku seseorang tanpa paksaan yang digambarkan sebagai sifat atau karakter kreatif seseorang (Sukarso dkk., 2019). Oleh karena itu, dalam penelitian ini yang bertujuan untuk mengetahui tingkatan awal kreativitas siswa yang ditinjau dari potensi disposisi kreatif siswa dan persepsi posisi disposisi kreatif siswa SMP dalam pendidikan IPA, yang akan diukur menurut lima aspek indikator disposisi kreatif oleh Lucas, Claxton dan Spencer (2013) yaitu keingintahuan (rasa ingin tahu yang tinggi), kolaboratif (dapat bekerjasama), kegigihan (tidak pantang menyerah), imajinatif (memiliki ide-ide yang tinggi) dan disiplin (mengikuti aturan).

\section{METODE PENELITIAN}

Penelitian ini menggunakan rancangan jenis penelitian deskriptif dengan metode survei. Metode ini dipilih untuk mendapatkan gambaran informasi awal tentang tingkatan potensi disposisi kreatif siswa dan persepsi posisi disposisi kreatif siswa dalam pendidikan IPA. Sampel yang diamati dalam penelitian ini berjumlah 73 siswa SMP di Palembang, Sumatera Selatan yang terdiri dari 45 siswa lakilaki dan 28 siswa perempuan. Data diperoleh melalui kuesioner tertutup yang dibagikan kepada siswa untuk mengetahui tingkatan disposisi kreatif siswa dan posisi yang dipersepsikan dari disposisi kreatif siswa yang dibandingkan dengan teman sebayanya. Instrumen kuesioner yang digunakan dalam penelitian ini merujuk pada instrumen yang dikembangkan oleh Lucas, Claxton dan Spencer (2013) yang menyusun menjadi lima indikator aspek disposisi dan posisi kreatif yaitu, keingintahuan, kegigihan, imajinatif, kolaboratif dan disiplin dan setiap aspek dikembangkan kembali menjadi 30 item pernyataan. Kuesioner sebelumnya dari kuesioner lain yang sesuai dapat digunakan untuk mengetahui posisi disposisi siswa dibandingkan dengan teman sebayanya. Pilihan jawaban yang diberikan pada siswa untuk menanggapi setiap item pernyataan dalam kuesioner yaitu berupa data kualitatif yang diubah menjadi kategori tertentu dengan mengacu pada kategorisasi oleh Arikunto (2010) 
dapat dilihat pada tabel 1. yang ditunjukkan dibawah ini.

Tabel 1. Rubrik penilaian (a) Disposisi Kreatif (b) Posisi Disposisi Kreatif

\begin{tabular}{ccc}
\hline $\begin{array}{c}\text { (a) Kategori } \\
\text { disposisi } \\
\text { kreatif }\end{array}$ & $\begin{array}{c}\text { (b) Kategori } \\
\text { posisi } \\
\text { disposisi } \\
\text { kreatif }\end{array}$ & Skor \\
\hline Selalu & Jauh Lebih Tinggi & 5 \\
\hline Sering & Lebih Tinggi & 4 \\
\hline Kadang-Kadang & Sama & 3 \\
\hline Jarang & Lebih Rendah & 2 \\
\hline Tidak Pernah & Jauh Lebih Rendah & 1 \\
\hline
\end{tabular}

Untuk mempermudah dalam menilai maka skala 1-5 akan dikonversikan menjadi skor kualitatif dengan mengikuti panduan yang ditampilkan pada tabel 2 .

Tabel 2. Tingkat Kualifikasi Kategori Disposisi Kreatif dan Posisi Disposisi Kreatif Siswa

\begin{tabular}{ccc}
\hline $\begin{array}{c}\text { Skala konversi } \\
\mathbf{1 0 0}\end{array}$ & $\begin{array}{c}\text { Kategori } \\
\text { kuantitatif } \\
\text { disposisi } \\
\text { kreatif }\end{array}$ & $\begin{array}{c}\text { Kategori } \\
\text { Posisi } \\
\text { Disposisi } \\
\text { Kreatif }\end{array}$ \\
\hline $90<\mathrm{x} \leq 100$ & $\begin{array}{c}\text { Sangat Tinggi } \\
\text { Jauh diatas }\end{array}$ \\
\hline $80<\mathrm{x} \leq 89$ & Tinggi & diatas \\
\hline $65<\mathrm{x} \leq 79$ & Rata-rata & Rata-rata \\
\hline $55<\mathrm{x} \leq 64$ & Rendah & dibawah \\
\hline $0<\mathrm{x} \leq 54$ & Sangat Rendah & Jauh dibawah \\
\hline
\end{tabular}

HASIL DAN PEMBAHASAN

Tingkat disposisi kreatif dan posisi disposisi kreatif siswa dibandingkan dengan teman sebayanya

Aspek keseluruhan dari pernyataan disposisi kreatif dan posisi disposisi kreatif siswa dibandingkan dengan teman sebayanya kemudian dianalisis berdasarkan 30 item pernyataan yang telah dikembangkan sebelumnya. Hasilnya dapat diamati secara umum pada gambar 1 .

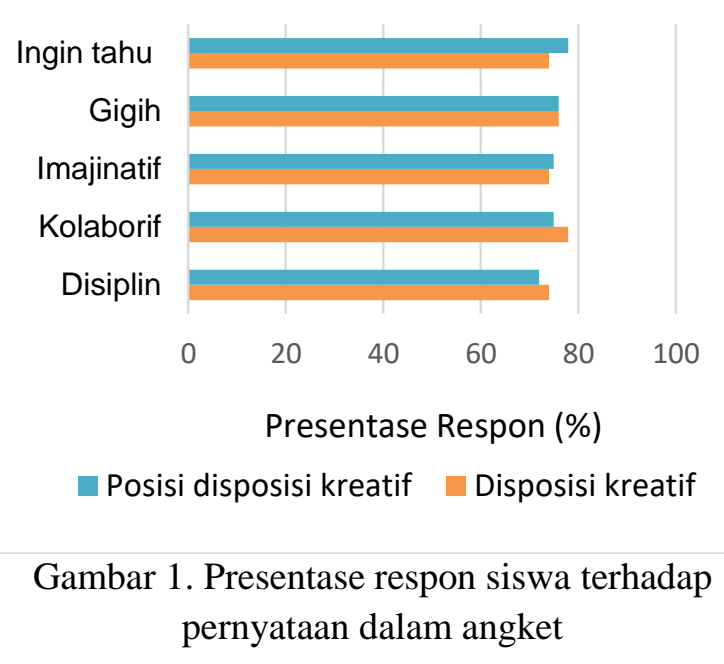

Berdasarkan hasil yang ditunjukkan pada Gambar 1 didapatkan informasi bahwa skor ratarata presentase disposisi kreatif dan posisi disposisi kreatif siswa secara umum memperoleh $75 \%$ berada pada kategori baik. Jika ditinjau dari setiap aspek indikator secara terperinci disposisi kreatif dan posisi disposisi kreatif berada pada tingkat frekuensi kemunculan yang hampir sama. Kemunculan yang cukup mencolok terjadi pada indikator keingintahuan dan kolaboratif yang mendapatkan skor rata-rata $78 \%$ dalam ketegori tinggi.

Hal ini sejalan dengan penelitian terbaru yaitu tentang kreativitas siswa yang menyatakan bahwa untuk dapat memecahkan masalah bersama maka, siswa harus dibekali dan dipupuk dalam proses kooperatif yang dapat memotivasi rasa ingin tahu, minat dan kebebasan siswa untuk saling berbagi pendapat dengan orang lain (Kang, 2020). Kolaborasi yang kreatif dengan adanya interaksi antara siswa, guru dan teman sebaya akan menghasilkan nilai positif yang dapat mempengaruhi kreativitas siswa (Chang, 2013). Ditambahkan oleh penelitian Putman dan Burke (1992) yang mengidentifikasi empat jenis disposisi dimana salah satunya terdapat disposisi kooperatif atau disposisi yang mengajarkan siswa untuk dapat bekerja sama dengan baik membangun kolaboratif antara satu dengan yang lainnya. 
Untuk itu, rasa ingin tahu yang tinggi dan sikap kolaboratif yang erat harus dimiliki oleh setiap siswa agar dapat meningkatkan disposisi dan kreativitas siswa. Sedangkan dapat dilihat dari grafik presentase rata-rata skor pada indikator disiplin mendapatkan skor yang paling rendah dari indikator lainnya yaitu sebesar $75 \%$ dengan kategori sedang mendekati rendah. Yang artinya kedisiplinan dalam pembelajaran masih harus ditingkatkan kembali dalam setiap pembelajaran dan perencanaan pembelajaran di sekolah. Untuk itu dalam penelitian sebelumnya juga dinyatakan bahwa pentingnya perencanaan pembelajaran yang kreatif dimana menjadi dasar bagi guru untuk diterapkan dalam pembelajaran (Sukarso dkk., 2019).

Tingkat disposisi kreatif dan posisi disposisi kreatif siswa dibandingkan dengan teman sebayanya berdasarkan jenis kelamin

(a) Siswa Laki-laki

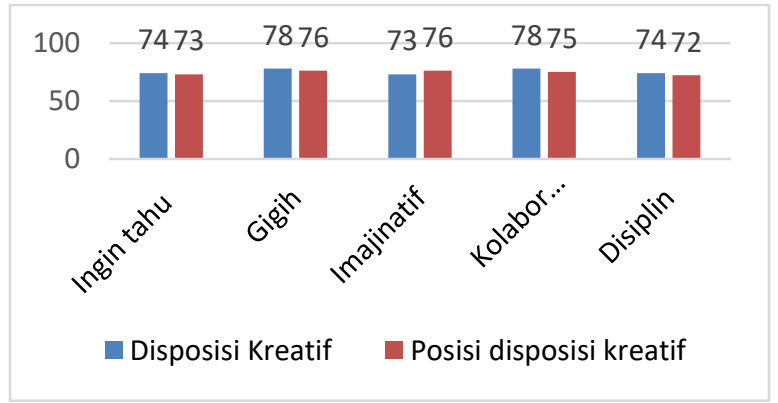

(b) Siswa Perempuan

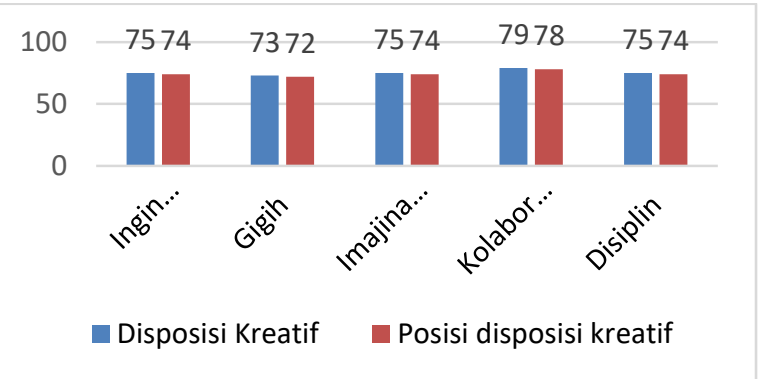

Gambar 2. Distribusi presentase disposisi kreatif dan posisi disposisi kreatif (a) Kelompok siswa laki-laki dan (b) kelompok siswa perempuan

Disposisi kreatif dan posisi disposisi kreatif merupakan dua kompetensi yang masih harus ditingkatkan dan dikembangkan dalam konteks kreativitas. Disposisi kreatif dapat bekorelasi dengan pemikiran kreatif, persepsi kreatif dan lingkungan kelas yang kreatif juga dapat memunculkan korelasi positif (Kang, 2020). Disposisi kreatif juga diharapkan dapat berkorelasi dengan proses dan produk kreatif terkait kreativitas dalam bidang tertentu (Sukarso, 2019). Karena kreativitas tidak hanya terdapat dalam sistem otak kita saja, akan tetapi muncul dalam sebuah interaksi pemikiran seseorang dalam konteks sosial dan budaya (Csikszentmihalyi, 1996).

Berdasarkan Gambar 2, dapat diamati bahwa tingkat disposisi kreatif siswa dan posisi disposisi kreatif siswa dibandingkan dengan teman sebayanya terkait jenis kelamin mendapatkan perolehan skor yang cenderung sama dengan kategori sedang. Akan tetapi, ratarata skor pada setiap indikatornya mengalami perbedaan. Dapat dilihat pada kelompok siswa laki-laki indikator kegigihan dan kolaboratif mendapatkan skor paling tinggi dibandingkan dengan indikator lainnya berada pada skor yang relatif sama. Pada kelompok siswa perempuan juga terlihat skor yang paling tinggi pada indikator kolaboratif sedangkan skor yang sama terdapat pada indikator keingintahuan, kegigihan, disiplin dan imajinatif.

Berdasarkan hasil temuan ini dapat disimpulkan bahwa tidak ada perbedaan antara presentase skor siswa laki-laki dan perempuan dalam konteks kreativitas keduanya mendapatkan presentase seimbang dan rata-rata yang sama. Seperti penelitian sebelumnya ditemukan, dalam literatur penelitiannya bahwa tidak ada hasil yang akurat dan konsisten antara perbedaan jenis kelamin antara laki-laki dan perempuan dari beberapa literatur kreativitas sehingga ukuran atau kategori yang sama dan seimbang menjadi hasil utamanya (Nakano dkk., 2021). Namun terdapat perbedaan pendapat dengan penelitian lainnya yang menyatakan 
bahwa tidak ada pengaruh yang signifikan antara variabel jenis kelamin ini terhadap kreativitas secara keseluruhan (Piaw, 2014) dan penelitian yang sama juga berpendapat bahwa pengaruh variabel jenis kelamin akan tergantung dengan jenis kreativitas yang dinilai (Fleith, 2008).

Oleh karena itu, dapat dikatakan bahwa kreativitas harus tetap dikembangkan dan ditanamkan dalam setiap individu terlepas dari adanya perbedaan jenis kelamin, sosial dan lingkungan yang ada. Temuan ini juga menunjukkan adanya perbedaan dalam setiap aspek indikator baik laki-laki maupun perempuan. Pada kelompok siswa laki-laki aspek kegigihan dan kolaboratif terlihat lebih dominan dari pada aspek lainnya, yang memiliki makna bahwa siswa laki-laki yang berani mencoba halhal baru, tidak mudah menyerah, menjadi lakilaki yang lebih tangguh, yang dapat memiliki kepercayaan diri yang tinggi. Sedangkan siswa perempuan pada aspek kolaboratif baik dari aspek disposisi dan posisi disposisi kreatifnya hal ini juga menunjukkan bahwa siswa perempuan memiliki lebih banyak peluang untuk membangun kerjasama yang baik dan berkreasi dengan teman sebayanya.

\section{KESIMPULAN}

Tingkat disposisi kreatif dan posisi disposisi kreatif siswa SMP dalam pembelajaran IPA berada pada kategori sedang. Dari ke lima aspek disposisi kreatif siswa, aspek keingintahuan memiliki skor tertinggi $78 \%$ dan pada posisi disposisi kreatif siswa skor tertinggi $78 \%$ pada aspek kolaboratif. Artinya kreativitas dalam pendidikan sains memerlukan strategi untuk mendukung tidak hanya pada pengetahuan dan keterampilan saja, akan tetapi disposisi dan posisi disposisi kreatif siswa juga harus dikembangkan baik dalam aspek keingintahuan, kegigihan, kolaboratif, imajinatif dan disiplin. Baik siswa laki-laki maupun perempuan memiliki rata-rata yang sama dan seimbang, akan tetapi pada siswa laki-laki lebih dominan pada aspek kegigihan dan kolaboratif sedangkan untuk siswa perempuan memiliki skor yang lebih dominan pada aspek kolaborasi saja.

\section{DAFTAR PUSTAKA}

Arikunto S. (2010). Prosedur Penelitian, Satuan Pendekatan dan Peraktek. Jakarta: Rineka Cipta.

Chang, Y. S. (2013). Student technological creativity using online problem-solving activities. International Journal of Technology and Design Education, 23(3), 803-816. https://doi.org/10.1007/s10798012-9217-5

Csikszentmihalyi. (1998). Creativity: Flow and the Psychology of Discovery and Invention - ProQuest. In Personnel Psycology (pp. 794-797).

http://search.proquest.com/docview/220140 121 ?pq-origsite $=$ gscholar

Fleith, D. de S. (2008). Características personológicas e fatores ambientais relacionados à criatividade do aluno do Ensino Fundamental. Aval. Psicol, 7(1), 35-44.

Florida, R., Mellander, C., \& King, K. (2015). The Global Creativity Index 2015. Martin Prosperity Institute, 53-57. http://martinprosperity.org/media/GlobalCreativity-Index-2015.pdf

Kang, E. J. (2020a). A multilevel analysis of factors affecting kindergartners' creative dispositions in relations to child-level variables and teacher-level variables. International Journal of Child Care and Education Policy, 14(1). https://doi.org/10.1186/s40723-020-00077-

Kang, E. J. (2020b). Analisis multilevel faktor yang mempengaruhi disposisi kreatif anak TK dalam kaitannya dengan variabel tingkat anak dan variabel tingkat guru. https://doi.org/10.1186/s40723-020-00077-

$$
\mathrm{z}
$$

Lawson, A. (2001). Promoting Creative and Critical Thinking Skills in College Biology. Bioscene, 27(1), 13-24.

Lucas, B., Claxton, G., \& Spencer, E. (2013). Progression in Student Creativity in School: First Steps Towards New Forms of Formative Assessments. OECD Education Working Papers, 86(86), 45. http://www.oecdilibrary.org/education/progression-in- 
student-creativity-in-

school_5k4dp59msdwk-en

Márquez, B. V., Ontiveros, M. Á. C., \& Pons, M. O. (2016). The small temples in the forum of Pollentia (Mallorca, Balearic Islands). Mélanges de l'École Française de Rome. Antiquité, 11(128-1), 53-74. https://doi.org/10.4000/mefra.3428

Mukhlis, M., \& Tohir, M. (2019). Instrumen Pengukur Creativity And Innovation Mathematic Skills Mahasiswa pada. Indonesian Journal of Mathematics and Natural Science Education, 1(2), 65-73.

Mumford, M. D., Antes, A. L., Caughron, J. J., Connelly, S., \& Beeler, C. (2010). Crossfield differences in creative problemsolving skills: A comparison of health, biological, and social sciences. Creativity Research Journal, 22(1), 14-26. https://doi.org/10.1080/1040041090357951 0

Nakano, T. de C., Oliveira, K. da S., \& Zaia, P. (2021). Gender Differences in Creativity: A Systematic Literature Review. Psicologia: Teoria e Pesquisa, 37, 1-10. https://doi.org/10.1590/0102.3772e372116

Noyes, D. (2000). Developing the disposition to be a reader: The educator's role. Clearinghouse on Early Education and Parenting. Online: Http://Ceep. Crc. Uiuc. Edu/Pubs/Katzsym/Noyes. Html, 313-317. http://ceep.crc.illinois.edu/pubs/katzsym/no yes.pdf

Piaw, C. Y. (2014). Effects of Gender and Thinking Style on Student's Creative Thinking Ability. Procedia - Social and Behavioral Sciences, 116, 5135-5139. https://doi.org/10.1016/j.sbspro.2014.01.10 87

Rhodes. (1961). Analysis of Creativity Can it be taught? Phi Delta Kappa International, 42(7), 305-310.

Robson, S., \& Rowe, V. (2012). Observing young children's creative thinking: Engagement, involvement and persistence. International Journal of Early Years Education, 20(4), 349-364. https://doi.org/10.1080/09669760.2012.743 098
Ros-Voseles, D. Da, \& Fowler-Haughey, S. (2007). Why Children's Dispositions Should Matter to All Teachers. Beyond the Journal NAEYC, September, 145-154.

Runco, M. A. (2003). Education for creative potential. International Journal of Phytoremediation, 47(3), 317-324. https://doi.org/10.1080/00313830308598

Suciani, M., \& Prima, E. (2020). Assessing Students' Creative Disposition and Creative Product in Learning Newton Law. October 2019. https://doi.org/10.4108/eai.12-102019.2296344

Sukarso, A., Widodo, A., Rochintaniawati, D., \& Purwianingsih, W. (2019a). The Contribution of Biological Practicum Learning Model Based On Creative Research Projects In Forming Scientific Creativity Of High School Students. 361369.

Sukarso, A., Widodo, A., Rochintaniawati, D., \& Purwianingsih, W. (2019b). The potential of students' creative disposition as a perspective to develop creative teaching and learning for senior high school biological science. Journal of Physics: Conference Series, 1157(2). https://doi.org/10.1088/1742$6596 / 1157 / 2 / 022092$

Undang-Undang No. 20 Tahun 2003. Sistem Pendidikan Nasional (Jakarta, Indonesia).

Wahyudi, W., Anugraheni, I., \& Winanto, A. (2018). Pengembangan Model Blended Learning Berbasis Proyek Untuk Menunjang Kreatifitas Mahasiswa Merancang Pembelajaran Matematika Sekolah Dasar. JIPM (Jurnal Ilmiah Pendidikan Matematika), 6(2), 68. https://doi.org/10.25273/jipm.v6i2.1766

Widodo, Ari. (2021). Pembelajaran Ilmu Pengetahuan Alam: Dasar-Dasar untuk Praktik.

Widodo, Ari. (2015). Mengembangkan Keterampilan Berpikir Siswa. Proceedings of Seminar Nasional Pendidikan MIPA 2015, 1-8. 